Introduction: Soluble Toll-like receptor 4 (STLR4) is a negative regulator of TLR4 signalling that has been reported in different diseases. In this study, we aimed to assess the serum levels of sTLR4 in hepatitis C virus (HCV)related hepatocellular carcinoma (HCC) and to investigate the correlation of sTLR4 with clinicopathological and biochemical parameters among HCV-related HCC patients and hepatitis $\mathrm{C}$ without HCC patients.

Material and methods: Fifty patients with HCV-related HCC, 50 patients with hepatitis $\mathrm{C}$ without HCC and 50 healthy control volunteers were enrolled. Clinicopathological and biochemical parameters were examined in all patients. Serum levels of sTLR4 were measured using enzyme-linked immunosorbent assay.

Results: A significant increase in serum sTLR4 was detected in patients with HCV-related HCC (4436.1 $\pm 7089.8) \quad(\mathrm{pg} / \mathrm{ml}) \quad \pm$ compared to the level in patients with hepatitis $C$ without HCC $(1561.4 \pm 532.0)(\mathrm{pg} / \mathrm{ml})$ $(p=0.002)$ and the level in the control group (1170.38 \pm 159.42$)(\mathrm{pg} / \mathrm{ml})$ $(p<0.001)$. Serum STLR4 was positively correlated with serum AST activity, serum direct bilirubin levels, serum alpha fetoprotein levels, tumour stages of HCC according to the Barcelona Clinic Liver Cancer staging system (BCLC), and the severity of liver cirrhosis according to the Child-Pugh classification among the patients with HCV-related HCC. The combination of serum alpha fetoprotein and serum STLR4 increased the sensitivity of HCC detection to $76 \%$ and the specificity to $94 \%$.

Conclusions: Serum STLR4 may be a marker for HCC susceptibility among HCV-infected patients.

Key words: AFP, HCV, HCC, sTLR4.

Contemp Oncol (Pozn) 2020; 24 (4): 216-220 DOI: https://doi.org/10.5114/wo.2020.102818

\section{Serum soluble Toll-like receptor 4 and the risk of hepatocellular carcinoma in hepatitis $C$ virus patients}

\author{
Maha Elkammah ${ }^{1}$, Ahmed Gowily ${ }^{2}$, Tarek Okda ${ }^{1}$, Maha Houssen ${ }^{1}$
}

${ }^{1}$ Department of Biochemistry, Faculty of Pharmacy, Damanhour University, Damanhour, Egypt

${ }^{2}$ Department of Clinical Oncology, Faculty of Medicine, Alexandria University, Alexandria, Egypt

\section{Introduction}

Hepatocellular carcinoma (HCC) is one of the most common types of liver cancer and is a significant cause of morbidity and mortality [1]. HCC accounts for $70.48 \%$ of all liver tumours among Egyptians [2] and is considered the second and sixth most prevalent cancer in men and women, respectively [3]. Chronic hepatitis C virus (HCV) infection is considered a major mediator of HCC pathogenesis worldwide [4].

Toll-like receptors (TLRs) are a family of pattern recognition receptors that are predominantly expressed on antigen-presenting cells. They are expressed by macrophages, neutrophils, natural killer (NK) cells, and mast cells of the innate-immune system; T- and B-lymphocytes of the adaptive branch; as well as by some nonimmune cells, as epithelial and endothelial cells [5].

Their signalling activates antigen-presenting cells to initiate an inflammatory response against invading pathogens [6]. TLR signalling plays a vital role in hepatocarcinogenesis [7]. TLR4 was the first human Toll homologue to be identified [8]. It is a vital mediator of the host inflammatory response to infection [9]. Increased TLR4 expression has been observed in virus-induced hepatitis [10] and in HCC [11].

The inflammatory response is a double-edged sword. While protective, excessive production of cytokines can be fatal for the host and is involved in a variety of immune disorders, allergies, and cancer [6]. Dynamic regulation of TLR signalling is important for the prevention of chronic inflammation and tissue destruction [12]. Numerous endogenous negative regulatory molecules controlling TLR responses have been characterised [13].

Soluble forms of some TLRs have been identified in various body fluids and cellular secretions [14], including serum, urine, tears, and saliva. These soluble TLRs are considered as negative regulators of TLR signalling [15]. Soluble TLR4 (sTLR4) ectodomain is generated via cleavage by metalloproteinases (ADAM17) in human [16-18] or by alternative splicing of the corresponding mRNAs in the mouse [19]. sTLR4 consists of 122 amino acids, of which 86 are identical to those of the extracellular domain of TLR4 [19]. The involvement of sTLR4 in HCC pathogenesis remains to be elucidated.

There were two aims of the present study. The first aim was to assess the serum levels of STLR4 in patients with HCV-related HCC, patients with hepatitis $C$ without HCC, and a group of healthy control volunteers. The second aim was to investigate the correlation between the serum STLR4 levels and biochemical and clinicopathological parameters in these patients. 


\section{Material and methods}

\section{Patients}

The present study was conducted on 150 individuals. Between January 2018 and March 2019, the patients were recruited from the outpatient clinic of Damanhour Oncology Center and Damanhour Fever Hospital. They comprised patients with recently diagnosed HCV-related HCC (HCC group, $n=50)$, patients with hepatitis $C$ without HCC (HCV group, $n=50)$, and healthy volunteers $(n=50)$. The latter were age- and sex-matched with the HCC and HCV groups of patients. Patients with HCC with a background of hepatitis B virus infection, history of alcohol consumption, other causes of chronic liver disease, schistosomiasis, chronic diseases that included diabetes mellitus, and autoimmune disease were excluded from the study. Patients with other malignancies and cardiac, respiratory, and renal diseases were also excluded. The study protocol was approved by the Ethics Committee of the Faculty of Pharmacy Damanhour University (320PB17). Written informed consent was obtained from all subjects enrolled in the study.

\section{Sample collection}

Five millilitres of whole blood was withdrawn from each participant. The serum samples of the withdrawn blood were individually collected in a sterile Eppendorf tube and stored at $-20^{\circ} \mathrm{C}$ until analyses, which included the levels of alpha fetoprotein (AFP) and STLR4 in one volume and the activities of liver enzymes (alanine aminotransferase [ALT] and aspartate aminotransferase [AST]), direct bilirubin levels, and albumin levels in the remaining volume.

\section{Analyses}

Liver function tests were performed using a Dimension RxL Max Autoanalyser (Siemens, USA) [20, 21]. Serum AFP levels were assayed using an ELISA kit (DSI S.r.l. Italy) and the ADVIA Centaur (Siemens, USA) [22]. Serum sTLR4 levels were determined using the human STLR4 ELISA Kit ( In-Hu4103; Inova, USA) [15] and HumaReader Single (HUMAN, Germany).

\section{Statistical analyses}

Data were fed to the computer and analysed using the SPSS software package version 20.0 (IBM, USA). Qualitative data are presented as numbers and percentages. Comparisons between different groups regarding categorical variables were tested using the Chi-square test. Quantitative data are described using mean and standard deviation (mean \pm standard deviation). For normal distribution, comparisons between more than two populations were analysed by F-test (ANOVA) and post hoc test (Tukey) for pairwise comparisons. For abnormally distributed quantitative variables, comparisons between more than two studied groups were analysed using the Kruskal Wallis test and post hoc (Dunn's multiple comparisons test) for pairwise comparisons. For abnormally distributed quantitative variables, comparisons between two studied groups were analysed using the Mann Whitney test. To correlate between two distributed abnormally quantitative variables
Spearman coefficient (r) was calculated. Receiver operating characteristic curve (ROC) statistics were applied to calculate the sensitivity and specificity to determine the diagnostic accuracy of the combination of biomarkers. The significance of the obtained results was judged at the $5 \%$ level.

\section{Results}

\section{Clinical characteristics}

The three groups were matched in age and sex (Table 1). A significant increase in ascites, jaundice, haematemesis, melena and hepatic encephalopathy recurrence was detected in the patients with HCC compared to the patients with hepatitis C without HCC $(p<0.05)$ (Table 1$)$. A significant increase in the severity of liver cirrhosis according to Child-Pugh classification was detected in the patients with HCC compared to the patients with hepatitis $C$ without HCC $(p<0.001)$ (Table 1). Tumour staging of the patients with HCC according to the Barcelona Clinic Liver Cancer (BCLC) staging system was stage C in $20 \%$ of the patients, stage $B$ in $38 \%$, and stage $A$ in $14 \%$ (Table 1 ).

\section{Biochemical analyse (liver function tests)}

A significant increase in serum ALT activity was detected in the patients with HCC $(69.54 \pm 21.75)(\mathrm{U} / \mathrm{l})$ compared to the activity in the patients with hepatitis $\mathrm{C}$ without HCC $(46.0 \pm 17.87)(\mathrm{U} / \mathrm{I})$ and the activity in the control group $(20.70 \pm 4.94)(U / I)(p<0.001)$ (Table 2). A significant increase in serum AST activity was detected in the patients with HCC (83.04 \pm 22.56$)(\mathrm{U} / \mathrm{l})$ compared to the activity in the patients with hepatitis C without HCC $(51.83 \pm 22.47)(\mathrm{U} / \mathrm{l})$ and the activity in the control group $(24.32 \pm 7.74)(\mathrm{U} / \mathrm{l})(p$ $<0.001$ ) (Table 2). A significant decrease in serum albumin level was detected in the patients with HCC $(2.35 \pm 0.597)$ $(\mathrm{gm} / \mathrm{dl})$ compared to the levels in the patients with hepatitis C without HCC $(3.88 \pm 0.85)(\mathrm{gm} / \mathrm{dl})(p<0.001)$ and the levels in the control group $(4.74 \pm 0.41)(\mathrm{gm} / \mathrm{dl})(p<0.001)$ (Table 2). A significant increase in serum direct bilirubin level was detected in the patients with HCC $(2.50 \pm 1.18)(\mathrm{mg} / \mathrm{dl}) \mathrm{com}$ pared to the level in the patients with hepatitis $C$ without HCC $(0.45 \pm 0.18)(\mathrm{mg} / \mathrm{dl})$ and the level in the control group $(0.31 \pm 0.15)(\mathrm{mg} / \mathrm{dl})(p<0.001)($ Table 2$)$

\section{Serum AFP}

A significant increase in serum AFP level was detected in the patients with hepatitis C without HCC (7.02 \pm 2.99$)$ $(\mathrm{ng} / \mathrm{ml})$ and the patients with HCV-related HCC (289.89 $\pm 691.26)(\mathrm{ng} / \mathrm{ml})$ compared to the level in the control group $(2.73 \pm 1.14)(\mathrm{ng} / \mathrm{ml})(p<0.001)$ (Table 3$)$. A significant increase in serum AFP level was also detected in the patients with HCV-related HCC $(289.89 \pm 691.26)(\mathrm{ng} / \mathrm{ml})$ compared to that in the patients with hepatitis $\mathrm{C}$ without HCC $(7.02 \pm 2.99)(\mathrm{ng} / \mathrm{ml})(p<0.001)$ (Table 3).

\section{Serum sTLR4}

The serum STLR4 level was significantly increased in the patients with hepatitis C without HCC $(1561.4 \pm 532.0)$ $(\mathrm{pg} / \mathrm{ml})$ and the patients with HCC (4436.1 \pm 7089.8$)(\mathrm{pg} /$ 
Table 1. Clinical characteristics

\begin{tabular}{|c|c|c|c|c|c|c|c|c|}
\hline \multirow[t]{2}{*}{ Characteristics } & \multicolumn{2}{|c|}{ Control $(n=50)$} & \multicolumn{2}{|c|}{$\begin{array}{l}\text { Patients with hepatitis C } \\
\text { without HCC } \\
(n=50)\end{array}$} & \multicolumn{2}{|c|}{$\begin{array}{l}\text { Patients with HCV- } \\
\text { related HCC } \\
(n=50)\end{array}$} & \multirow[t]{2}{*}{ Test of sig. } & \multirow[t]{2}{*}{$p$} \\
\hline & $n$ & $\%$ & $n$ & $\%$ & $n$ & $\%$ & & \\
\hline \multicolumn{9}{|l|}{ Gender } \\
\hline Male & 28 & 56.0 & 32 & 64.0 & 39 & 78.0 & $\chi^{2}=5.526$ & 0.063 \\
\hline Female & 22 & 44.0 & 18 & 36.0 & 11 & 22.0 & & \\
\hline Age (years) & $F=2.038$ & 0.134 & & & & & & \\
\hline Mean \pm SD. & $49.82 \pm 7.03$ & $51.70 \pm 9.28$ & $53.06 \pm 7.70$ & & & & & \\
\hline Jaundice & & & 3 & 6.0 & 15 & 30.0 & $\chi^{2}=9.756^{*}$ & $0.002^{*}$ \\
\hline Ascites & & & 2 & 4.0 & 34 & 68.0 & $\chi^{2}=44.444^{*}$ & $<0.001^{*}$ \\
\hline Hematemesis and melena & & 3 & 6.0 & 16 & 32.0 & $\chi^{2}=10.981^{*}$ & $0.001^{*}$ & \\
\hline Hepatic encephalopathy & & 2 & 4.0 & 14 & 28.0 & $\chi^{2}=10.714^{*}$ & $0.001^{*}$ & \\
\hline A & & 45 & 90.0 & 0 & 0 & & & \\
\hline B & & 5 & 10.0 & 36 & 72.0 & & & \\
\hline Child-Pugh classification & C & 0 & 0 & 14 & 28.0 & $\chi^{2}=82.439$ & ${ }^{*}<0.001^{*}$ & \\
\hline \multirow[t]{4}{*}{$\mathrm{BCLC}$ staging } & A & & & 7 & 14.0 & & & \\
\hline & $\mathrm{B}$ & & & 19 & 38.0 & & & \\
\hline & C & & & 10 & 20.0 & & & \\
\hline & D & & & 14 & 28.0 & & & \\
\hline
\end{tabular}

Child-Pugh-classification of liver cirrhosis, BCLC-Barcelona Clinic Liver Cancer staging system, F-ANOVA test, $p$-value for comparing between the studied groups, "statistically significant at $p \leq 0.05$

Table 2. Biochemical parameters of the three studied groups

\begin{tabular}{|c|c|c|c|c|c|}
\hline Characteristics & Control $(n=50)$ & $\begin{array}{l}\text { Patients with hepatitis C } \\
\text { without HCC } \\
(n=50)\end{array}$ & $\begin{array}{l}\text { Patients with HCV-related } \\
\text { HCC } \\
(n=50)\end{array}$ & Test of sig. & $p$-value \\
\hline $\operatorname{ALT}(U / I)$, mean $\pm S D$ & $20.70 \pm 4.94$ & $46.0 \pm 17.87$ & $69.54 \pm 21.75$ & $F=109.535^{*}$ & $<0.001^{*}$ \\
\hline $\mathrm{AST}(\mathrm{U} / \mathrm{I})$, mean $\pm \mathrm{SD}$ & $24.32 \pm 7.74$ & $51.83 \pm 22.47$ & $83.04 \pm 22.56$ & $H=107.496^{*}$ & $<0.001^{*}$ \\
\hline Albumin $(\mathrm{gm} / \mathrm{dl})$, mean $\pm \mathrm{SD}$ & $4.74 \pm 0.41$ & $3.88 \pm 0.85$ & $2.20 \pm 0.58$ & $F=201.361^{*}$ & $<0.001^{*}$ \\
\hline D.Bil. $(m g / d l)$, mean $\pm S D$ & $0.31 \pm 0.15$ & $0.45 \pm 0.18$ & $2.50 \pm 1.18$ & $H=107.789^{*}$ & $<0.001^{*}$ \\
\hline Sig. bet. grps & \multicolumn{5}{|c|}{$p_{1}<0.05^{*}, p_{2}<0.001^{*}, p_{3}<0.001^{*}$} \\
\hline
\end{tabular}

ALT - alanine aminotransferase, AST-aspartate aminotransferase, D.Bil - direct bilirubin, F-ANOVA test, H-Kruskal-Wallis test, pairwise comparison bet. each 2 groups was done using Post Hoc Test, $p$ - $p$-value for comparing between the studied groups, $p_{1}$ - $p$-value for comparing between control and HCV, $p_{2}$ - $p$-value for comparing between the control and HCC, $p_{3}-p$-value for comparing between the HCV and HCC, "statistically significant at $p \leq 0.05$

Table 3. Serum AFP and serum sTLR4 levels of the three studied groups

\begin{tabular}{|c|c|c|c|c|c|}
\hline Parameter & Control $(n=50)$ & $\begin{array}{c}\text { Patients with hepatitis C } \\
\text { without HCC }(n=50)\end{array}$ & $\begin{array}{l}\text { Patients with HCV- } \\
\text { related HCC }(n=50)\end{array}$ & Test of sig. & $p$-value \\
\hline $\operatorname{AFP}(n g / m l)$, mean \pm SD & $2.73 \pm 1.14$ & $7.02 \pm 2.99$ & $289.89 \pm 691.26$ & $H=102.955^{*}$ & $<0.001^{*}$ \\
\hline Serum sTLR4 $(\mathrm{pg} / \mathrm{ml})$, mean $\pm \mathrm{SD}$ & $1170.38 \pm 159.42$ & $1561.4 \pm 532.0$ & $4436.1 \pm 7089.8$ & $H=104.742^{*}$ & $<0.001^{*}$ \\
\hline Sig. bet. grps & \multicolumn{5}{|c|}{$p_{1}<0.001^{*}, p_{2}<0.001^{*}, p_{3}<0.05^{*}$} \\
\hline
\end{tabular}

$\mathrm{ml}$ ) compared to the level in the control group (1170.38 $\pm 159.42)(\mathrm{pg} / \mathrm{ml})(p<0.001)$ (Table 3). A significant increase in the level of serum STLR4 was detected in the patients with HCC $(4436.1 \pm 7089.8)(\mathrm{pg} / \mathrm{ml})$ compared to the level in the patients with hepatitis C without HCC (1561.4 $\pm 532.0)(\mathrm{pg} / \mathrm{ml})(p=0.002)$ (Table 3).

\section{Correlation of serum STLR4 levels with} biochemical and clinicopathological parameters

Correlation analysis within patients with HCC revealed a significant positive correlation between STLR4 and serum AST activity, serum direct bilirubin, and serum AFP levels $(p \leq 0.05)$. Serum sTLR4 was positively correlated with 
the severity of liver cirrhosis according to the Child-Pugh classification and tumour stages of HCC according to the BCLC staging system $(p \leq 0.05)$. For patients with hepatitis $C$ without HCC, a significant positive correlation was found only between serum sTLR4 level and serum direct bilirubin levels $(p \leq 0.05)$.

\section{Diagnostic performance of the markers}

ROC analysis (Fig. 1) to assess the sensitivity and specificity of serum AFP and serum STLR4 revealed an area under the curve of 0.865 for AFP and 0.768 for TLR4 in the discrimination between the group of patients with hepatitis C without HCC and the group of patients with HCV-related HCC. Using a cut-off value $>1488.5 \mathrm{pg} / \mathrm{mL}$, sTLR4 had a sensitivity of $62 \%$ and specificity of $88 \%$. At a cut-off value $>9.91$, AFP displayed a sensitivity of $74 \%$ and specificity of $80 \%$. The combination of serum AFP and serum STLR4 increased the sensitivity of HCC detection to $76 \%$ and the specificity to $94 \%$ with an increase of the area under the curve to 0.889 .

\section{Discussion}

TLR4 is expressed by immune cells in normal conditions, but its expression can be induced on hepatocytes and epithelial parenchyma cells ectopically during HCV infection [23]. Ectopic expression of TLR4 is associated with an increased risk of HCC in HCV-infected animal models [23]. The non-structural 5A (NS5A) HCV protein downregulates the expression of NKG2D on natural killer (NK) cells via an interaction with TLR4. Down-regulation of NKG2D leads to decreased functions of NK cells and increases the chance of HCC progression [24]. TLR4 expression is upregulated in HCC tissues [11] and its signalling promotes cancer cell survival and proliferation through the modulations of the nuclear factor-kappa B and mitogen-activated protein kinase signalling pathways in HCC [25].

The foregoing findings indicate that the TLR system must be tightly regulated in both the physiological and pathological states. Without this tight regulation, reactions that are either insufficient or excessive lead to severe or lethal events $[11,26]$. To the best of our knowledge, this is the first study investigating serum STLR4 levels as an endogenous negative modulator of TLR4 signalling in HCV-related HCC and its correlation with clinicopathological parameters in these patients.

Patients with hepatitis C without HCC and patients with HCV-related HCC had high serum levels of sTLR4 compared to the control group. This was most significantly elevated in the HCV-related HCC group. This may be suggestive of the role of STLR4 signalling in HCC progression. The soluble form of TLR4 has been considered as negative regulator of TLR function [27]. sTLR4 inhibits TLR4-mediated signaling, possibly by interfering with receptor-ligand associations [28]. In a study involving a mouse macrophage cell line, the presence of soluble form of TLR4 significantly reduced LPS-induced nuclear factor- $\mathrm{\kappa B}(\mathrm{NF}-\kappa \mathrm{B})$ activation and tumor necrosis factor (TNF) production, suggesting that soluble form of TLR4 is involved in regulating TLR signaling $[13,19]$.
A previous study investigated the clinical significance of serum STLR4 in non-small cell lung cancer (NSCLC) patients [8]. The patients displayed significantly higher serum levels of sTLR4 compared to the levels in the healthy control group. Several studies showed that overexpression of TLR4 in HCC cell lines and in human HCC tissues [11, 25]. Consequently, sTLR4 was rapidly elevated in the serum of HCC patients as a feedback mechanism because sTLR4 dampens inflammation by disrupting TLR-mediated pro-inflammatory responses [29]. This result agrees with a prior study [27] in which STLR4 was rapidly elevated in the plasma upon the administration of lipopolysaccharide, like pro-inflammatory cytokines [29]. It is conceivable that the counter-regulatory mechanisms mediated by STLRS extend to the interference with endogenous TLR ligands. This may imply that these anti-inflammatory mechanisms are regulated at different levels and are potential complementary strategies to reduce inflammation [27].

Concerning the correlation between STLR4 and clinicopathological parameters, significant positive correlations of sTLR4 with serum AST activity, serum total bilirubin, serum direct bilirubin, and serum AFP levels were detected in the group of patients with HCV-related HCC. For the patients with hepatitis $C$ without HCC, a significant positive correlation was found only between serum sTLR4 levels and serum total and direct bilirubin levels. Moreover, significant positive correlations were found between serum sTLR4 levels and the severity of liver cirrhosis according to the Child-Pugh classification and tumour stages of HCC according to BCLC staging. This was in agreement with the previous results of a positive correlation between serum STLR4 levels and tumour stage in patients with stage I-III NSCLC [8].

In the present study, serum sTLR4 levels showed a high specificity (88\%) in discriminating between patients with

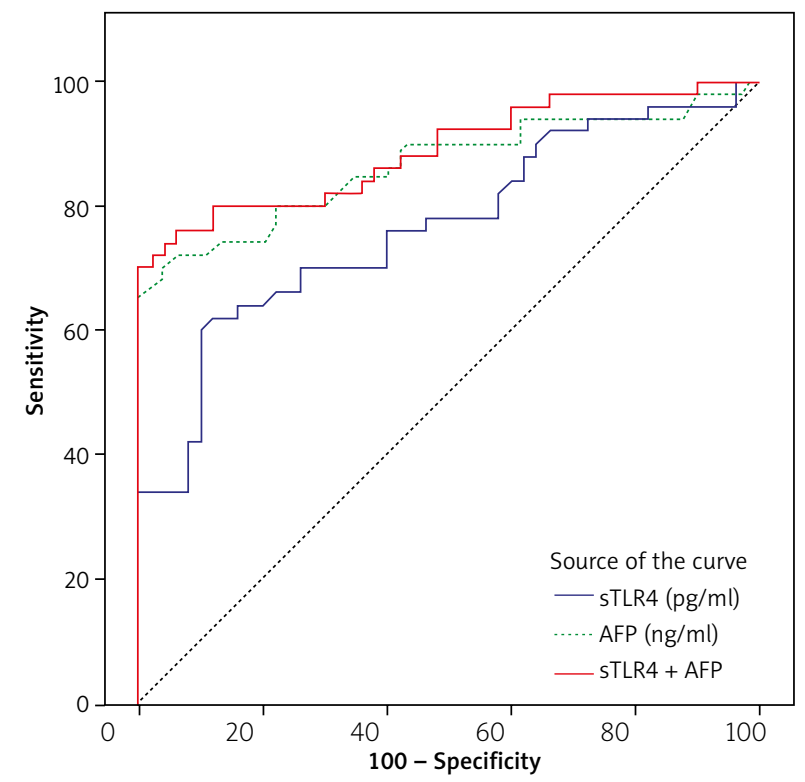

Fig. 1. ROC curve for serum AFP and serum STLR4 in the discrimination between the patients with hepatitis $\mathrm{C}$ without HCC and the patients with HCV-related HCC 
HCV-related HCC and patients with hepatitis C without HCC, using high cut-off values, but the sensitivity was low. The combination of serum AFP and serum STLR4 increased the sensitivity of HCC detection to $76 \%$ and the specificity to $94 \%$ with increased area under the curve (0.889), indicating that serum STLR4 plays an active role in HCC pathogenesis and could potentially be a marker of susceptibility for HCC.

\section{Conclusions}

In conclusion, STLR4 is an endogenous negative regulator of TLR4 signalling that may also be a susceptible diagnostic and prognostic marker, in combination with AFP, for HCV-related HCC patients. Further studies with larger patient cohorts are warranted to validate the role of STLR4 as a susceptible marker and as a promising target for immune therapy in HCV-related HCC patients.

\section{Acknowledgements}

We acknowledge the effort of Asst. Prof. Dr. Doaa Ali Abdelmonsif, assistant professor of biochemistry, Faculty of Medicine, Alexandria University, for her valuable support.

\section{The authors declare no conflict of interest.}

\section{References}

1. Poulou LS, Botsa E, Thanou I, et al. Percutaneous microwave abla tion vs radiofrequency ablation in the treatment of hepatocellular carcinoma. World J Hepatol 2015; 7: 1054

2. Holah NS, El-Azab DS, Aiad HA, Sweed DM. Hepatocellular carcinoma in Egypt: epidemiological and histopathological properties. Menoufia Med J 2015; 28: 718.

3. Hammam O, Magdy M, Anas A, et al. Expression of hnRNPK \& Claudin-4 in HCV-Induced Early HCC and Adjacent Liver Tissue. Maced J Med Sci 2017; 5: 595.

4. Siddiqui MA, Siddiqui HH, Mishra A, Usmani A. Epidemiology of hepatocellular carcinoma. Virus 2018; 18:19.

5. Leifer CA, Medvedev AE. Molecular mechanisms of regulation of Toll like receptor signaling. J Leukoc Biol 2016; 100: 927-941.

6. Kaisho T, Akira S. Toll-like receptor function and signaling. J Allergy Clin Immunol 2006; 117: 979-987.

7. Yang L, Xu XG, Zhang JG, et al. Accumulating evidence: TLR signaling facilitates the development of hepatocellular carcinoma. Int J Clin Exp Med 2016; 9: 4107-4112.

8. Wei F, Yang F, Li J, et al. Soluble Toll-like receptor 4 is a potential serum biomarker in non-small cell lung cancer. Oncotarget 2016; 7: 40106.

9. Pimentel-Nunes P, Soares JB, Roncon-Albuquerque Jr R, et al. Tolllike receptors as therapeutic targets in gastrointestinal diseases. Expert Opin Ther Targets 2010; 14: 347-368.

10. Soares J-B, Pimentel-Nunes P, Afonso L, et al. Increased hepatic expression of TLR2 and TLR4 in the hepatic inflammation-fibrosis-carcinoma sequence. Innate Immun 2012; 18: 700-708.

11. Kang Y, Su G, Sun J, Zhang Y. Activation of the TLR4/MyD88 signaling pathway contributes to the development of human hepatocellular carcinoma via upregulation of IL-23 and IL-17A. Oncol Lett 2018: 15: 9647-9654.

12. Huang Q, Pope RM. Toll like receptor signaling: a potential link among rheumatoid arthritis, systemic lupus, and atherosclerosis. J Leukoc Biol 2010; 88: 253-262.

13. Anwar MA, Basith S, Choi S. Negative regulatory approaches to the attenuation of Toll-like receptor signaling. Exp Mol Med 2013; 45: e11.
14. Zunt SL, Burton LV, Goldblatt LI, et al. Soluble forms of Toll-like receptor 4 are present in human saliva and modulate tumour necrosis factor- $\alpha$ secretion by macrophage-like cells. Clin Exp Immunol 2009; 156: 285-293.

15. AlQallaf H, Hamada Y, Blanchard S, et al. Differential profiles of soluble and cellular toll like receptor (TLR)-2 and 4 in chronic periodontitis. PLoS One 2018; 13: e0200231.

16. Yang WS, Kim JJ, Lee MJ, Lee EK, Park SK. Ectodomain Shedding of RAGE and TLR4 as a Negative Feedback Regulation in High-Mobility Group Box 1-Activated Aortic Endothelial Cells. Cell Physiol Biochem 2018; 51: 1632-1644.

17. Yang WS, Kim JJ, Lee MJ, Lee EK, Park SK. ADAM17-Mediated Ectodomain Shedding of Toll-Like Receptor 4 as a Negative Feedback Regulation in Lipopolysaccharide-Activated Aortic Endothelial Cells. Cell Physiol Biochem 2018; 45: 1851-1862.

18. Hayashida K, Bartlett AH, Chen Y, Park PW. Molecular and cellular mechanisms of ectodomain shedding. Anat. Rec. Adv Integr Anat Evol Biol 2010; 293: 925-937.

19. Iwami K, Matsuguchi T, Masuda A, et al. Cutting edge: naturally occurring soluble form of mouse Toll-like receptor 4 inhibits lipopolysaccharide signaling. J Immunol 2000; 165: 6682-6686.

20. Murray RL. Alanine aminotransferase. In: Clinical Chemistry: Theory, Analysis, and Correlation. $2^{\text {nd }}$ ed. Kaplan LA, Pesce AJ (eds.). St. Louis CV Mosby Co. 1989: 895-898.

21. Gendler S. Uric acid. Kaplan A, et al. Clin Chem CV Mosby Co. St Louis. Toronto. Princet 1984: 1268-1273.

22. Uotila M, Ruoslahti E, Engvall E. Two-site sandwich enzyme immunoassay with monoclonal antibodies to human alpha-fetoprotein. J Immunol Methods 1981; 42: 11-15.

23. Tsukamoto H, Mishra L, Machida K. Alcohol, TLR4-TGF- $\beta$ antagonism, and liver cancer. Hepatol Int 2014; 8: 408-412.

24. Imran M, Waheed Y, Manzoor S, et al. Interaction of Hepatitis C virus proteins with pattern recognition receptors. Virol J 2012; 9: 126.

25. Wang L, Zhu R, Huang Z, et al. Lipopolysaccharide-induced toll-like receptor 4 signaling in cancer cells promotes cell survival and proliferation in hepatocellular carcinoma. Dig Dis Sci 2013; 58: 2223 2236.

26. Houssen ME, El Mahdy RH, Shahin DA. Serum soluble toll like receptor 2: a novel biomarker for systemic lupus erythematosus disease activity and lupus related cardiovascular dysfunction. Int J Rheum Dis 2016; 19: 685-692.

27. ten Oever J, Kox M, van de Veerdonk FL, et al. The discriminative capacity of soluble Toll-like receptor (STLR) 2 and sTLR4 in inflammatory diseases. BMC Immunol 2014; 15: 55.

28. Hyakushima N, Mitsuzawa $\mathrm{H}$, Nishitani C, et al. Interaction of soluble form of recombinant extracellular TLR4 domain with MD-2 enables lipopolysaccharide binding and attenuates TLR4-mediated signaling. J Immunol 2004; 173: 6949-6954.

29. Raby A-C, Le Bouder E, Colmont C, et al. Soluble TLR2 reduces inflammation without compromising bacterial clearance by disrupting TLR2 triggering. J Immunol 2009; 183: 506-517.

\section{Address for correspondence}

\section{Maha Houssen}

Department of Biochemistry

Faculty of Pharmacy

Damanhour University

Damanhour, El Beheira Governorate, Egypt

e-mail: mahahoussen@yahoo.com

Submitted: 27.07 .2020

Accepted: 13.09 .2020 